\title{
DOI | 10.21680/1981-1802.2020v58n56ID20030 \\ A taxa de alfabetização de Antônio Prado, Rio Grande do Sul (1895-1920)
}

\author{
Manuela Ciconetto Bernardi \\ Terciane Ângela Luchese \\ Universidade de Caxias do Sul (Brasil)
}

\section{Resumo}

artigo tem como objetivo analisar as taxas de alfabetização da cidade de Antônio Prado, Rio Grande do Sul, entre os anos de 1895 e 1920. Como colônia ocupada por imigrantes e descendentes a partir de 1886, em sua maioria provenientes do norte da Itália, Polônia e outros grupos com menor representatividade, Antônio Prado passou a ser um município a partir de 1899. Empregamos a análise documental histórica do conjunto de registros civis de matrimônios pesquisados num arco temporal de vinte e cinco anos como metodologia. A verificação das assinaturas dos cônjuges nos registros civis de matrimônios gerou dados classificados por sexo, idade, nacionalidade e "assinou/não assinou". O grupo amostral foi de 3.068 indivíduos. Em síntese, constatou-se que a taxa de alfabetização variava conforme a nacionalidade, o sexo e o ano e que, nesta localidade, a maioria assinou os documentos e houve manutenção da taxa no período analisado, perfazendo uma média de $60 \%$ de documentos assinados.

Palavras-chave: Analfabetismo. Taxa de alfabetização. Imigrantes. Cidade de Antônio Prado.

\section{The literacy rate of Antônio Prado city, state of Rio Grande do Sul (1895-1920)}

\section{Abstract}

The article aims to analyze the literacy rates in the city of Antônio Prado, state of Rio Grande do Sul, between the years 1895 and 1920. As a colony occupied by immigrants and descendants from 1886, mostly from northern Italy, Poland and other groups with less representativeness. Antônio Prado became a municipality from 1899. We used a historical documentary analysis of the set of civil marriage records surveyed in a twenty-five years period as methodology. The verification of spouses' signature in the civil matrimonial records generated data classified by sex, age, nationality and "signed / unsigned". The sample group was 3,068 individuals. In summary, it was found that the literacy rate varied according to nationality, sex and year analyzed and, in this location, the majority signed the documents and the rate was maintained during the analyzed period, making an average of $60 \%$ of signed documents.

Keywords: Illiteracy. Literacy rate. Immigrants. Antônio Prado city. 


\section{La tasa de alfabetización en la ciudad de Antônio Prado, Estado de Rio Grande do Sul (1895-1920)}

\section{Resumen}

Este artículo tiene como objeto analizar las tasas de alfabetización de la ciudad de Antônio Prado, estado de Rio Grande do Sul, entre los años de 1895 y 1920. Como colonia ocupada por inmigrantes y descendientes a partir de 1886, principalmente del norte de Italia, Polonia y otros grupos con menos representatividad, Antônio Prado se convirtió en municipio a partir de 1899. Utilizamos el análisis documental histórico del conjunto de los registros civiles de los matrimonios investigados en un período de veinticinco años como metodología. La verificación de las firmas de los cónyuges en los registros civiles de los matrimonios generó datos clasificados por sexo, edad, nacionalidad y "firmado / no firmado". El grupo de muestra fue de 3.068 individuos. En resumen, se constató que la tasa de alfabetización variaba conforme la nacionalidad, el sexo y el año analizado, y que, en esa localidad, la mayoría firmó los documentos y la tasa se mantuvo durante el período analizado, con un promedio de $60 \%$ de los documentos firmados.

Palabras claves: Analfabetismo. Tasa de alfabetización. Inmigrantes. Ciudad de Antônio Prado.

\section{Introdução}

O presente artigo realiza um estudo sobre a taxa de alfabetização da localidade Antônio Prado, Rio Grande do Sul entre os anos de 1895 e 1920, o que permite pensar o seu processo de escolarização. Antônio Prado foi criada em 1886, na serra gaúcha, constituindo-se na última das antigas colônias ocupadas prioritariamente por imigrantes que deixaram a península itálica e ali se estabeleceram.

Primeiramente, problematizamos, a partir de Ferraro e Kreidlow (2004), as categorias de analfabetismo e alfabetização, em que aspectos imbricados sinalizam um desacordo amplo sobre o reconhecimento dos conceitos e a escolha do estudo do problema (analfabetismo) ou da solução (alfabetização). Aqui, utilizamos o termo "taxa de alfabetização", a partir de Chartier (1991), porém, preferimos empregar os dois conceitos em alguns casos - analfabetismo e alfabetização. A "taxa de alfabetização" seria o primeiro indicador de algum conhecimento de escrita. Em seguida, problematizamos o entendimento sobre as formas de alfabetização ou analfabetismo.

Para o estudo, utilizamos as acepções da História Cultural que suscitam a utilização de novas abordagens, objetos e possibilidades de pesquisa (BURKE, 1992; CERTEAU, 2002). Os documentos utilizados para a produção da 
taxa de alfabetização são recenseamentos e censos em sua maioria, porém, tornar-se-iam inviáveis neste estudo, tendo em vista a necessidade de calcular, com alguma regularidade, e responder às questões propostas, salvo a existência de diversos censos da localidade, que inexistem. A opção documental foi, então, pelos registros civis de casamento.

A operação historiográfica a partir de documentos gerados para outro fim - registros civis de matrimônios -, viabiliza e indica potencial na perspectiva da História Cultural, na medida em que o historiador, como construtor, lapida o material para o fim que deseja (FEBVRE, 1989). Questiona, analisa, compara e vai compondo pelos rastros que que the chegam, uma narrativa histórica. Ademais, apesar de voltar a tratar de objetos já investigados, com a ampliação das abordagens e dos documentos, houve, nas últimas décadas, uma renovação nas pesquisas da História da Educação, além de sua aproximação com a História Cultural (CATTANI; FARIA FILHO, 2002). Ao colocarmos contribuições de ambas em diálogo, acreditamos que potencializamos as investigações com relevantes resultados acerca dos processos educativos e históricos.

Dessa forma, problematizamos algumas questões norteadoras deste estudo pensando nas taxas de alfabetização. Quem eram os indivíduos alfabetizados da localidade e em qual período? Existem diferenças com relação à alfabetização entre as nacionalidades que compõem o quadro estatístico da população? Tendo vista se tratar da análise de ambos os sexos, seria possível verificar o quão alfabetizadas as mulheres eram em comparação com os homens? Em virtude da amostra incluir informações anuais dessa porcentagem e por Antônio Prado ter recebido uma grande quantidade de imigrantes, é possível fazer um comparativo entre os indivíduos nascidos no local e também aferir a taxa de alfabetização transnacional através das porcentagens obtidas, pensando em imigrantes e as primeiras gerações de seus filhos? Com essas indagações, o estudo oferece uma contribuição histórica ao analisar as taxas de alfabetização de habitantes de Antônio Prado entre os anos de 1895 e 1920.

Reconhecemos que o estudo proposto não é a primeira investigação a utilizar essas mesmas abordagem e fonte para a realização de uma análise dos registros de casamento na produção das taxas de alfabetização. Outros pesquisadores o fizeram precedidos por governos de estados, conforme aponta Vincent (2014), ainda no século XX, com o intuito de mensurar a porcentagem de assinaturas nos registros civis e buscar a compreensão dos índices para sua 
aplicação em campanhas de alfabetização. Quando pensamos nas taxas de alfabetização, com a ressalva posta por Chartier,

As porcentagens de assinaturas pacientemente coletadas [...] são: indicadores culturais macroscópicos, compósitos, que não medem exatamente nem a difusão da capacidade de escrever, mais restrita do que os números indicam, nem a da leitura, que é mais extensa (CHARTIER, 1991, p. 144).

Considerando tal advertência e movimentando o termo "taxa de alfabetização" na análise, entendemos os fatores envolvidos, conforme citado por Chartier (1991), e os limites para penar a capacidade de escrita e leitura. Desse modo, na medida que essa forma de produção de documento é analisada, nos permite ter acesso a alguns indicadores para abordar um quantificador amplo, buscando nos vestígios, nos detalhes, para que nos remetam ao processo de escolarização, apontem de forma abrangente a alfabetização ocorrida (ou não), mesmo que de maneira rudimentar. Nos interessa compreender algumas nuances da escrita, seu uso e disseminação, em Antônio Prado, sem entrar na especificidade da alfabetização pela quantificação do aprendi$4 \quad$ zado adquirido pelo indivíduo.

\section{A taxa de alfabetização por meio dos registros civis de matrimônios}

Para entender a produção e finalidade do corpus utilizado neste estudo, buscamos brevemente um histórico da execução dos registros civis de matrimônios no território nacional, principalmente no que tange à obrigatoriedade da assinatura dos cônjuges. A normativa que sancionou o recenseamento da população no Império foi a Lei n . 1.829, de 09 de setembro de 1870. No Art. $2^{\circ}$, se encontra a criação da Diretoria Geral de Estatística como responsável pela organização dos quadros de nascimentos, casamentos e óbitos. Com base nessa Lei e, mais especificamente no Artigo supracitado, o Decreto $n^{\circ}$. 9.886, editado em 07 de março de 1888, continha as diretrizes de como deveria ser executado o registro civil de nascimento, casamento e óbito. $\bigcirc$ Art. $11^{\circ}$ do Decreto define: 
As partes ou seus procuradores assinarão estes assentos com seus nomes por inteiro, e assim também as testemunhas, nos casos em que são necessárias. Se, contudo, alguma destas pessoas não puder escrever por qualquer circunstância, far-se-á declaração disto no assento, assinando a rogo outra pessoa (BRASIL. DECRETO $\mathrm{N}^{\circ}$ 9.886, DE O7 DE MARÇO DE 1888, p. 248).

Já o Decreto n. 10.044, de 22 de setembro de 1888, determinou a obrigatoriedade da execução do registro civil em todo o Império a partir de 01 de janeiro de 1889. A Lei e Decretos supramencionados permaneceram em vigor ao longo do período analisado, sendo revogados pelo Decreto $\mathrm{n}$. 4.827, de 07 de fevereiro de 1924, que incluiu todas as informações acerca do sistema de registros brasileiro em um só documento. É possível perceber que, em 1870, foi regulamentada a execução dos registros civis e que, após quase duas décadas, se estabeleceram as diretrizes para a padronização desses registros - que determinaram a assinatura, bem como a obrigatoriedade da execução do próprio registro.

Os registros se iniciaram em Antônio Prado apenas em 1895, seis anos após à emancipação do município e obrigatoriedade da efetivação do assentamento. Antes dessa data, a responsabilidade era da jurisdição ao qual pertencia, Vacaria, Rio Grande do Sul, distante 60 quilômetros da sede. Dessa forma, os residentes tinham que a percorrer essa distância para a execução formal das certidões. Em 1895 se estabeleceram duas formas de registros civis na localidade: os registros de casamentos em dezoito de fevereiro e os nascimentos em dois de abril do mesmo ano. Os registros de óbitos passaram a ser realizados quatro anos depois, em 14 de fevereiro de 1899.

Possuíam o mesmo padrão persistindo uma ordenação por data do registro, informações sobre os presentes, nome do cônjuge, filiação, nome do cônjuge e encerramento. As informações complementares variavam como é o caso da nacionalidade dos pais e residência. Para exemplificação, transcreve-se um registro de 1916 em Antônio Prado:

Aos dezoito dias do mês de Novembro de mil novecentos e dezesseis [...] receberam-se em matrimônio o cidadão Fidelcino Magnabosco, com dona Julia Rech, ele com vinte e um anos de idade, solteiro, agricultor, filho legítimo de Pietro Magnabosco, já falecido neste termo e de Delícia Araldi, italiana, aqui residente e ela a contraente com dezoito anos de idade, solteira, de profissão 
doméstica, filha legítima de Rech Giuseppe e de Maria Muzzato, italianos, agricultores, aqui residentes, ambos os contraentes naturais deste Estado, residentes neste município e abaixo assinados (CERTIDÃO DE CASAMENTO DE FIDELCINO MAGNABOSCO E JULIA RECH, 1916).

Considerando o exemplo anterior e o conjunto de dados auferidos em documentos como esses, foi possível desenvolver a análise. Com relação às assinaturas, todos os registros de Antônio Prado contemplam o/a cônjuge ou testemunha, assim, apesar do início tardio da execução das certidões no local, estas seguiram as orientações prescritas pelo Decreto $n^{\circ} .9 .886,1888$ e suas diretrizes.

Pensando nessa relação, Ragazzini (2001, p. 19) declara que "[...] as assinaturas dos registros matrimoniais, estudadas com o objetivo de determinar os níveis de analfabetismo [...] são fontes [...] para a história da escola e da educação [...]". Já Ferraro e Kreidlow (2004, p. 180) explicam que "[...] por menor que seja o ganho representado pela alfabetização, medida pelo critério de saber ler e escrever um bilhete simples, ele representa o primeiro passo - decisivo - no processo de escolarização". Dessa maneira, a taxa de alfabetização produzida neste estudo segue uma perspectiva de análise ampla, conforme explanado, relacionada ao primeiro acesso à escolarização.

Temos ciência de algumas especificidades em relação à fonte documental: limitação por idade, já que contempla apenas indivíduos que se casam; e restrição ao indicar apenas se assinou ou não assinou, sem medir o grau de leitura e escrita. Destacamos os seguintes pontos positivos: possibilidade de verificar diferenças por nacionalidade e sexo; abertura de diálogos sobre a alfabetização transnacional; e inclusão de uma amostra populacional considerável. Também há um ganho considerável por termos condições de verificar continuidades (ou descontinuidades) dos percentuais, a cada ano e a cada década, além de observar as possíveis mudanças entre os que assinaram ou não de uma geração para outra.

Posto isto, a produção da taxa de alfabetização por meio de registros civis é um indicador que pode trazer informações sobre o nível de alfabetização da localidade, uma vez que a ausência de censos regulares, recenseamentos e informações acerca da alfabetização dos indivíduos dificultam a avaliação. 
Postas essas questões, torna-se relevante um olhar relativo para o contexto e as informações produzidas sobre o limite espacial e temporal.

\section{O contexto e a alfabetização}

Antônio Prado é um município localizado no nordeste do Rio Grande do Sul, possui uma ocupação recente e é considerada a "[... última das antigas colônias da imigração italiana no Rio Grande do Sul". Os primeiros estabelecimentos de imigrantes ocorreram em 1886 (PAZUCH, 2015). Eram pessoas que já haviam colonizado outros locais da mesma região (GASTAL; BEBER; SÁ, 2017) com rápidos movimentos e medidas administrativas para a ocupação do seu território. Dessa forma, desde os primeiros anos, existem na região atividades manufatureiras, comerciais e, predominantemente, agrícolas. A população era composta em sua maioria por imigrantes oriundos da península itálica, além de poloneses, em menor número, e brasileiros (BARBOSA, 1980). O rápido crescimento e autonomia administrativa culminou na emancipação política de Antônio Prado em 1899.

Após a emancipação, as duas primeiras décadas do século XX foram marcadas pelo recesso econômico, em parte, devido à Primeira Guerra Mundial que impactou o município e à abertura de novas frentes de imigração. Dessa forma, o local, assim como os municípios limítrofes, sofreu com o êxodo de uma quantidade expressiva de habitantes. A Tabela a seguir apresenta uma tendência à redução populacional registrada em 1913, especialmente devido às novas frentes migratórias para o noroeste gaúcho, oeste catarinense e paranaense.

Tabela 1

População de Antônio Prado presente nos registros

\begin{tabular}{|c|c|}
\hline Ano & Quantidade de habitantes \\
\hline Início de 1887 & 486 \\
\hline 1900 & 8.331 \\
\hline 1905 & 10.000 \\
\hline 1913 & 7.974 \\
\hline 1917 & 8.950 \\
\hline
\end{tabular}

Fonte: Elaborado pelas autoras com base em Annuario (1888). Recenseamento (1913) e Estatísticas (1918). 
A localidade que viu o seu crescimento e auge até a data de emancipação (1899), passou a sofrer com apreensão o recesso por meio de fatores internos e externos em nível econômico, social, cultural, político e educacional. Esse panorama permaneceu até meados de 1920, recorte deste estudo, quando a situação começou a melhorar aos poucos.

São escassas as pesquisas sobre Antônio Prado que concernem à escolarização. Alguns estudos são de memorialistas e, mesmo assim, o tema principal não foi a educação. No início do século XX, um relato ao Ministério das Relações Exteriores da Itália de Luigi Petrocchi (1904, p. 15-16, tradução nossa), que foi professor e agente consular em Bento Gonçalves (município próximo), informou que, em Antônio Prado, "[...] o analfabetismo atinge 90\% não podendo os pobres habitantes a permitir-se o luxo de uma escola".

Ao afirmar isso, Petrocchi, por meio de um relatório consular, generalizou uma informação que permanecerá em relatos e memórias, confirmando que a maioria da população era analfabeta. Outro ponto a ser considerado é a tradição oral que manteve a imagem do "colono' analfabeto" que teria se mobilizado em torno do trabalho e do catolicismo com pouca ou quase nenhuma atenção à escola. Luchese (2008) afirma que a escola foi desejada 8 pelos imigrantes e descendentes, concluindo que o processo escolar público, gratuito e em português era requisitado pela maioria das comunidades.

De acordo com Veiga (2007), na época da Proclamação da República existiam por volta de $85 \%$ de analfabetos no país. Os dados do INEP - Instituto Nacional de Estudos e Pesquisas Educacionais Anísio Teixeira (2003) situam a marca do início do século XX em 65,3\% de jovens e adultos analfabetos. Já de acordo com Ferraro e Kreidlow (2004), de 1890 até 1920 o estado do Rio Grande do Sul foi um dos que apresentou uma das maiores quedas na taxa de analfabetismo. Esta constância é verificada em outros locais no Brasil pela análise dos censos demográficos (FERRARO, 2002), apesar do Rio Grande do Sul, em conjunto com outros estados como São Paulo e Rio de Janeiro, liderar os índices mais baixos de analfabetismo do período (FERRARO; KREIDLOW, 2004).

Na serra gaúcha, alguns estudos e discussões sobre o analfabetismo e a alfabetização, como é o caso dos trabalhos de Piazza e Ribeiro (2005) e Pazuch (2015), dão ênfase ao grupo de italianos que eram na maioria analfabetos. Segundo De Boni e Costa (1984), o alfabetismo era inferior a 
50\%, porém, autores como Luchese (2008), Timm (2013) e Possamai (2005) sustentam a partir de documentos que os imigrantes eram alfabetizados em sua maioria.

Gardelin e Costa (1993) têm a mesma interpretação, apesar de alertarem para um empobrecimento cultural das primeiras gerações de filhos. Dois estudos sobre a taxa de alfabetização merecem destaque por apresentar quantificadores semelhantes à nossa pesquisa. O primeiro é de Luchese (2008) que questiona o reiterado analfabetismo entre imigrantes, analisando o recenseamento das Colônias Conde D'Eu e Dona lsabel que obteve o resultado de 74\% de homens alfabetizados em 1883. O segundo é o estudo de Giron (1977) que utilizou os mapas estatísticos de Caxias do Sul para afirmar que 63\% dos homens eram alfabetizados entre 1875 e 1886.

Portanto, há divergências no que tange às taxas de alfabetização do período, considerando-se a região e os grupos estudados. Assim, se torna necessária a exploração da temática, seja por meio de contribuições locais para o apoio na construção de um panorama regional e nacional, seja por investigações e levantamentos da temática explorando as pesquisas já realizadas que elucidem a compreensão da alfabetização. A seguir, apresentamos a metodologia utilizada na medição da taxa de alfabetização em Antônio Prado - as escolhas, o período, o uso, a construção e o tratamento do corpus para a análise documental histórica.

Para a construção do corpus de análise do estudo, foram contabilizadas as assinaturas de cônjuges dos primeiros vinte e cinco anos de registros civis de matrimônios de Antônio Prado. $O$ intervalo de amostragem da taxa de alfabetização do município foi de 1895 a 1920, período de existência do registro civil, tempo que consideramos suficiente.

A pesquisa foi realizada por meio dos registros civis de matrimônios do acervo da lgreja de Jesus Cristo dos Santos dos Últimos Dias, que possui o maior acervo genealógico do mundo, online e em centros físicos. No nosso caso, as informações foram obtidas online, através do site da lgreja. Os livros fonte com os manuscritos estão no cartório de registros civis de Antônio Prado onde foram digitalizados pela Igreja entre os anos de 1984 e 2003. Estão guardados em rolos de microfilmes de $35 \mathrm{~mm}$ e $16 \mathrm{~mm}$, disponibilizados online a partir da última década. 
As informações correspondentes ao período e tipologia analisados neste estudo estão nos cinco primeiros livros ${ }^{2}$ de registros de matrimônios civis da localidade. Estes, foram analisados um a um, com a leitura das informações constantes no ato completo, sendo deles compiladas as informações no que tange ao ano, sexo, nacionalidade, idade e se o indivíduo assinou ou não assinou o documento. Utilizamos uma linha para cada indivíduo, conforme mostra o primeiro registro analisado (Quadro 1).

Quadro 1

Tabulação dos dados

\begin{tabular}{|c|c|c|c|c|}
\hline Ano & Sexo & Nacionalidade & Idade & $\begin{array}{c}\text { A s s in ou / Não } \\
\text { assinou }\end{array}$ \\
\hline 1895 & Masculino & Italiano & 24 & Assinou \\
\hline 1895 & Feminino & Italiana & 20 & Não assinou \\
\hline
\end{tabular}

Fonte: Elaborado pelas autoras

Nos registros originais, os manuscritos utilizam o termo "sabe ler e 10 escrever" ou "não sabe ler e escrever", porém utilizamos "assinou" ou "não assinou" neste estudo tanto na tabulação quanto na discussão. Essa escolha ocorreu por dois motivos: por considerarmos a contribuição de Chartier (1991, p. 144) em que explicita que a taxa não mede a "capacidade de escrever"; e pela nossa escolha, pois são sinais das primeiras formas de alfabetização, até mesmo para não relacionar a pesquisa a um conceito de estudo sobre escrita ou grafia.

Os dados ainda foram obtidos em ordem cronológica e a compilação foi registrada em um programa de computador para o gerenciamento de dados, que possibilita a geração de tabelas e planilhas. Ao término, foram obtidas informações de 3.068 indivíduos, 1.534 matrimônios ao longo de vinte e cinco anos. Com os dados analisados e coletados, seguiram-se cinco estágios, também realizados no mesmo software para a produção das informações. Os dados isolados não trariam elementos para discussão, então, foi imprescindível um agrupamento para a análise pormenorizada.

Outra escolha foi como apresentar o resultado quantitativo das informações: em número individuais, números totais ou porcentagem. Nos pareceu indiscutível que a visualização e compreensão da porcentagem seria mais 
assertiva, assim, os resultados serão exibidos dessa forma, com exceção do estágio de análise 1, devido à especificidade proposta. Os estágios de análise são: 1) nacionalidades presentes nos registros; 2) assinaturas totais; 31 assinaturas por nacionalidade; 4) assinaturas por sexo; e 5) assinaturas por ano de nascimento. Esses estágios foram construídos tendo em vista as questões propostas. A seguir, discutiremos os elementos resultantes do estudo.

\section{As taxas de alfabetização, uma análise}

A primeira análise proposta, a verificação dos dados construídos com as informações dos registros civis matrimoniais, ocorreu devido à necessidade de compreender acerca da nacionalidade para responder ao questionamento sobre quais nacionalidades compunham o quadro estatístico dentro dos registros civis da localidade. E não se refere propriamente à taxa de alfabetização como um número indicador, mas se torna necessária à medida que proporciona um panorama geral dos indivíduos. Por esse motivo não trabalhamos com porcentagem, mas, sim, com números. Como resultado, obtivemos as informações apresentadas na Tabela seguinte.

Tabela 2

Nacionalidades presentes nos registros

\begin{tabular}{|c|c|}
\hline Nacionalidade & Total \\
\hline Alemães & 3 \\
\hline Brasileiros & 195 \\
\hline Espanhóis & 3 \\
\hline Franceses & 1 \\
\hline Germano- brasileiros & 5 \\
\hline Italianos & 1301 \\
\hline Ítalo-Brasil- brasileiros & 3 \\
\hline Ítalo-Brasileiros & 1438 \\
\hline Ítalo-polono-brasileiros & 3 \\
\hline Poloneses & 83 \\
\hline Polono-brasileiros & 23 \\
\hline
\end{tabular}


Tabela 2

Nacionalidades presentes nos registros (continuação)

\begin{tabular}{|c|c|}
\hline Nacionalidade & Total \\
\hline Portugueses & 1 \\
\hline Sírios & 1 \\
\hline Sueco-brasileiros & 1 \\
\hline Suecos & 6 \\
\hline Uruguaios & 1 \\
\hline
\end{tabular}

Fonte: Elaborado pelas autoras a partir dos dados obtidos nos registros civis

Como é possível observar, o contingente populacional da localidade é, em sua maioria, composto por italianos e ítalo-brasileiros, seguido de brasileiros e poloneses com uma minoria de outras nacionalidades. Através dessa análise inicial, foi possível reafirmar que a localidade tinha um predomínio de imigrantes italianos e descendentes, seguido por poloneses, conforme apresentado por outros autores e estudos (BARBOSA, 1980; PAZUCH, 2015). As minorias são pouco ou brevemente citadas nos estudos explorados.

12 Com relação às nomenclaturas utilizadas, por ausência de termos que explicitem as nacionalidades (e respectivas ascendências), utilizamos: brasileiros para indivíduos nascidos no Brasil que possuem sobrenomes portugueses, espanhóis, ou indígenas; ítalo-Brasil-brasileiros para filhos de italianos e brasileiros nascidos no Brasil; e ítalo-polono-brasileiros para filhos de italianos e poloneses nascidos no Brasil.

segundo passo de análise foi relativo à uma compreensão global da taxa de alfabetização, que remetesse a todos os indivíduos que assinaram os documentos, ou não, com base na ideia de um "indicador macroscópico" de Chartier (1991) da alfabetização do local e do período. Assim obtivemos o resultado:

Tabela 3

Assinaturas totais

\begin{tabular}{|c|c|}
\hline Assinaram & Não assinaram \\
\hline $60,85 \%$ & $39,15 \%$ \\
\hline
\end{tabular}

Fonte: Elaborado pelas autoras a partir dos dados obtidos nos registros 
Dessa forma como um indicador, os indivíduos possuíam algum acesso à escrita em sua maioria. Isso demostra que existia um conhecimento ou acesso à alfabetização, seja por meio da escolarização, em um processo formal de ensino, seja por meio informal. Esse resultado difere das informações levantadas por Petrocchi (1904) que afirma ser 90\% da população analfabeta. Muitos autores, como Kreutz (2000) e outros, utilizaram Petrocchi (1904) como fonte porque são os únicos indicadores da alfabetização do local. Seus dados são questionados ou utilizados para novos estudos que procuram entender se os indivíduos eram ou não alfabetizados. Os índices cotejam pesquisas regionais e oferecem plausibilidade relativa aos resultados de Luchese (2008) e Giron (1977) que concluem que havia uma maioria alfabetizada. Em um valor comparativo entre o local, o regional e o nacional, podemos estabelecer as seguintes informações:

\section{Tabela 4}

\section{Taxa de analfabetismo 1890-1920}

\begin{tabular}{|c|c|c|c|}
\hline Ano & Brasil & Rio Grande do Sul & Antônio Prado \\
\hline 1890 & $82,6 \%$ & $69,7 \%$ & $X$ \\
\hline 1900 & $65,3 \%$ & $X$ & $67,11 \%$ \\
\hline 1920 & $65 \%$ & $53,8 \%$ & $63 \%$ \\
\hline
\end{tabular}

Fonte: Elaborado pelas autoras a partir de fontes

Porém, são necessários dois alertas. Existem diferenças no cálculo dos índices, alguns não explicitam a idade mínima estabelecida, outros contabilizam a população a partir dos 5 e 15 anos4. Além disso, Ferraro e Kriedlow (2004, p. 185) alertam que os índices de 1900 não são parâmetros seguros pois o "[...] sub-recenseamento de extensas áreas rurais em 1900 resultou em subestimação no analfabetismo". Por esse motivo não foram incluídas as informações do estado em 1900.

Com ciência dessas questões e sem considerar o índice regional, estadual e nacional como informações fidedignas, realizamos algumas considerações. É possível perceber que a entrada dos imigrantes no estado do Rio Grande do Sul teria reduzido a média de analfabetos e, tendo em vista que no país de origem tiveram contatos com alguma forma de escolarização, 
possivelmente, buscaram implementar alternativas para que os filhos também tivessem algum conhecimento escolar ao se estabelecer no Brasil. Podemos levar em conta que isso ocorreu em Antônio Prado também com a mesma sistemática. Ainda, chama a atenção, na tabela 4, a baixa alteração negativa de apenas $0,3 \%$ de analfabetos ocorrida no período de 20 anos no Brasil. E, finalizando o panorama comparativo de Antônio Prado, é possível verificar semelhanças com os índices do estado e do país.

Como indicador que apresenta um panorama geral da localidade, seguimos à procura de especificidades. Dessa forma, inicialmente analisamos as assinaturas por nacionalidades, com vista à pergunta: existiam diferenças de alfabetização entre as nacionalidades? As informações coletadas se encontram a seguir.

\begin{tabular}{|c|c|}
\hline \multicolumn{2}{|c|}{ Assinaturas por nacionalidade } \\
\hline Alemães & $66,67 \%$ \\
\hline Brasileiros & $58,46 \%$ \\
\hline Espanhóis & $33,33 \%$ \\
\hline Franceses & $100,00 \%$ \\
\hline Germano brasileiros & $60,00 \%$ \\
\hline Italianos & $64,57 \%$ \\
\hline Ítalo-Brasil-brasileiros & $66,67 \%$ \\
\hline Ítalo-brasileiros & $60,57 \%$ \\
\hline Ítalo-polono-brasileiros & $100,00 \%$ \\
\hline Poloneses & $13,25 \%$ \\
\hline Polono-brasileiros & $47,83 \%$ \\
\hline Portugueses & $100,00 \%$ \\
\hline Sírios & $100,00 \%$ \\
\hline Sueco-brasileiros & $0 \%$ \\
\hline Suecos & $100 \%$ \\
\hline Uruguaios & $100 \%$ \\
\hline
\end{tabular}

Fonte: Elaborado pelas autoras a partir dos dados obtidos nos registros civis

Para analisar os dados coletados na tabela 5, precisamos nos apoiar tabela 2, já que algumas nacionalidades possuem somente um indivíduo, o que não representa uma amostragem considerável para compreender ou tomar 
como certo que os indivíduos daquela nacionalidade saberiam assinar os documentos ou não. Assim, desconsideramos as seguintes categorias: franceses, portugueses, sírios, sueco-brasileiros e uruguaios. Incluímos seus dados nas tabelas porque entendemos que seria uma informação importante, apesar de não ser pertinente para a amostragem.

Em seguida, temos de 3 a 6 indivíduos analisados por nacionalidade alemã, espanhola, germano-brasileira, ítalo-Brasil-brasileira, ítalo-polono-brasileira e sueca que, em sua maioria, ultrapassam em $60 \%$ o índice de assinantes nos registros, com exceção dos espanhóis com 33\% de assinaturas. Passamos, então, a uma quantidade maior de indivíduos, que compõe as nacionalidades: polono-brasileiras, polonesas, brasileiras, italianas e ítalo-brasileiras que possuem indicadores díspares. Por esse motivo, vamos analisar os dados por várias perspectivas.

As menores taxas encontradas foram nos poloneses (13,25\%), polono-brasileiros $(47,83 \%)$ e espanhóis (33\%) que são os únicos indicadores com assinaturas abaixo de $50 \%$ dos dados analisados. A amostragem dos espanhóis corresponde a 3 indivíduos, sendo ainda baixa para uma conclusão a respeito dessa nacionalidade. Porém, o número analisado de poloneses e polono-brasileiros é alto, mostrando que a sua alfabetização difere, e muito, de outras nacionalidades.

Os pais imigrantes dos polono-brasileiros e poloneses chegaram ao Rio Grande do Sul com menores índices de alfabetização, enquanto os filhos, que receberam educação no Brasil, possuíam melhores índices, apesar desse número ainda estar aquém de representar a maior parte dos indivíduos desse grupo de amostragem. $O$ índice de polono-brasileiros é baixo e parece não contemplar devidamente o grupo quando se trata da alfabetização para filhos de imigrantes de outras nacionalidades, como germano-brasileiros, ítalo-brasil-brasileiros e ítalo-brasileiros. Supondo que existisse alguma forma de escolarização, ela não incluiu a maior parte dos filhos de poloneses, mas, mesmo assim, fez o índice dessa nacionalidade crescer em comparação com os seus pais.

Italianos e ítalo-brasileiros formam os grupos com maior número de indivíduos, suas porcentagens ficam na mesma dezena, entre $60 \%$ a $70 \%$, com uma diferença de $4 \%$ a mais para os italianos. Isso mostra que a maioria 
dos imigrantes italianos era alfabetizada e que houve movimentos de alfabetização que contemplaram os filhos desses imigrantes de alguma forma.

Apesar de não coletar informações referentes à profissão, o que chamou a atenção na coleta foi a presença de brasileiros executarem alguma atividade referente à administração pública do local. Em sua maioria $(58,64 \%)$ eram alfabetizados, o que demonstra a necessidade de leitura e escrita para a atividade desenvolvida. Os índices se aproximam da maior parte das nacionalidades presentes nos registros.

A terceira proposta de análise se refere às assinaturas por sexo. E ela se torna particularmente interessante ao passo que a alfabetização das mulheres à época é pouco investigada devido ao apagamento e silenciamento nos registros. Sua mensuração é árdua e poucas fontes possibilitam essa investigação. $\bigcirc$ resultado dessa medição é significativo, pois julgaríamos que eram alfabetizadas em sua maioria, caso seguíssemos as informações produzidas pelos números gerais produzidos até na época, o que infelizmente não é correto. A taxa de alfabetização das mulheres não se aproxima da taxa dos homens, conforme é possível verificar.

Tabela 6

Assinaturas por sexo

\begin{tabular}{|c|c|}
\hline \multicolumn{2}{|c|}{ Porcentagem que assinou } \\
\hline Homens & Mulheres \\
\hline $72,03 \%$ & $49,67 \%$ \\
\hline
\end{tabular}

Fonte: Elaborado pelas autoras a partir dos dados obtidos nos registros civis

Os números mostram que quase metade das mulheres eram alfabetizadas, sabiam assinar seu nome, o que não é um índice baixo. O que chama a atenção é a diferença entre o índice dos homens e das mulheres. Mas, se considerarmos as médias do Brasil na mesma época, o percentual é bem maior que o nacional. Sabe-se que a prioridade pela escolarização no final do século XX era dada ao homem em oposição à mulher. Ler e escrever era julgado algo "inútil" a quem deveria ficar presa aos afazeres domésticos. Silva (2010) verificou em seu estudo a ausência das meninas na escola. Excluídas do ensino, a maioria não recebia instrução, e as poucas que recebiam eram 
educadas dentro das suas próprias casas (PAIVA, 2003). Em Antônio Prado, os números não indicam algo diferente, a abertura das escolas priorizava as aulas masculinas (CORRESPONDÊNCIA, 1890), o que reflete na porcentagem da tabela 6.

último estágio de análise foram os documentos assinados de acordo com o ano de nascimento de cada cônjuge incluem os nascidos de 1845 até 1904, correspondentes aos registros de matrimônios de 1895 a 1920. Os dados revelam menos de 20 indivíduos por ano até 1870. Nessa década, o número sobe para mais de 50 nascidos por ano, com picos acima de 100 após 1880, diminuindo após 1900 para menos de 50 indivíduos por ano. A maior idade de um cônjuge foi de 64 anos e a menor de 14 anos, os noivos tinham uma média de 22 anos de idade.

Para esse estágio, primeiramente, todos os indivíduos foram separados por ordem de nascimento. Depois, foram geradas as tabelas separadas por ano de nascimento e calculadas as porcentagens de assinaturas de cada ano. Esse estágio foi pensado para atentar à questão da transmigração, já que um indivíduo que declarava ter nascido fora do Brasil não necessariamente foi educado ou passou por uma escola no seu país de origem, tendo em vista que pode ter nascido no exterior e migrado com poucos meses, ou anos, antes do seu processo de alfabetização. E neste estudo, em específico, é melhor ser enquadrado como filho de imigrante, isto é, em outra classificação em que foi registrado no documento.

Assim, a concepção desse estágio do estudo deu-se para verificar hipoteticamente se existiam diferenças nas porcentagens de um indivíduo que foi alfabetizado fora do Brasil e outro que foi alfabetizado no Brasil. Sabemos das diferenças nos anos em que cada um migrou, mas seria possível perceber diferenças nos anos com essa separação se houvesse discrepâncias perceptíveis. Não foram analisadas as especificidades de cada nacionalidade, queríamos, de forma geral, entender se existiriam diferenças referentes ao imigrante e seu filho no que tange à educação se incluíssemos todos os dados. $\bigcirc$ resultado da primeira análise foi: 
Tabela 7

Assinaturas por ano de nascimento

\begin{tabular}{|c|c|c|c|}
\hline \multicolumn{4}{|c|}{ Assinaturas por ano de nascimento } \\
\hline 1845 & $33 \%$ & 1877 & $63 \%$ \\
\hline 1846 & $100 \%$ & 1878 & $70 \%$ \\
\hline 1848 & $100 \%$ & 1879 & $59 \%$ \\
\hline 1849 & $100 \%$ & 1880 & $65 \%$ \\
\hline 1850 & $67 \%$ & 1881 & $64 \%$ \\
\hline 1851 & $100 \%$ & 1882 & $59 \%$ \\
\hline 1853 & $40 \%$ & 1883 & $59 \%$ \\
\hline 1854 & $33 \%$ & 1884 & $60 \%$ \\
\hline 1855 & $67 \%$ & 1885 & $62 \%$ \\
\hline 1857 & $50 \%$ & 1886 & $53 \%$ \\
\hline 1858 & $75 \%$ & 1887 & $52 \%$ \\
\hline 1859 & $57 \%$ & 1888 & $58 \%$ \\
\hline 1860 & $45 \%$ & 1889 & $56 \%$ \\
\hline 1861 & $75 \%$ & 1890 & $51 \%$ \\
\hline 1862 & $67 \%$ & 1891 & $62 \%$ \\
\hline 1863 & $67 \%$ & 1892 & $64 \%$ \\
\hline 1864 & $83 \%$ & 1893 & $55 \%$ \\
\hline 1865 & $60 \%$ & 1894 & $61 \%$ \\
\hline 1866 & $47 \%$ & 1895 & $61 \%$ \\
\hline 1867 & $65 \%$ & 1896 & $62 \%$ \\
\hline 1868 & $69 \%$ & 1897 & $55 \%$ \\
\hline 1869 & $79 \%$ & 1898 & $60 \%$ \\
\hline 1870 & $57 \%$ & 1899 & $66 \%$ \\
\hline 1871 & $64 \%$ & 1900 & $65 \%$ \\
\hline 1872 & $63 \%$ & 1901 & $74 \%$ \\
\hline 1873 & $74 \%$ & 1902 & $70 \%$ \\
\hline 1874 & $72 \%$ & 1903 & $44 \%$ \\
\hline 1875 & $56 \%$ & 1904 & $0 \%$ \\
\hline 1876 & $64 \%$ & & \\
\hline
\end{tabular}

Fonte: Elaborado pelas autoras a partir dos dados obtidos nos registros civis 
Percebe-se que os dados esparsos não dizem muito por si só, é necessária a geração de um gráfico de tendências. Todavia, alguns anos não servem de parâmetro, já que possuem uma baixa taxa de nascimento (até 10), o que induz à análise incorreta de dados. Dessa forma, desconsideramos os anos 1845 a 1858, 1860, 1903 e 1904, e geramos um gráfico de dispersão com uma linha de tendência média móvel (período 3), porque a maioria se refere aos anos iniciais e finais. Assim, apresentamos a tendência dos anos que serão tomados como base para a análise com maior clareza.

\section{Gráfico 1}

\section{Gráfico de assinaturas por ano}

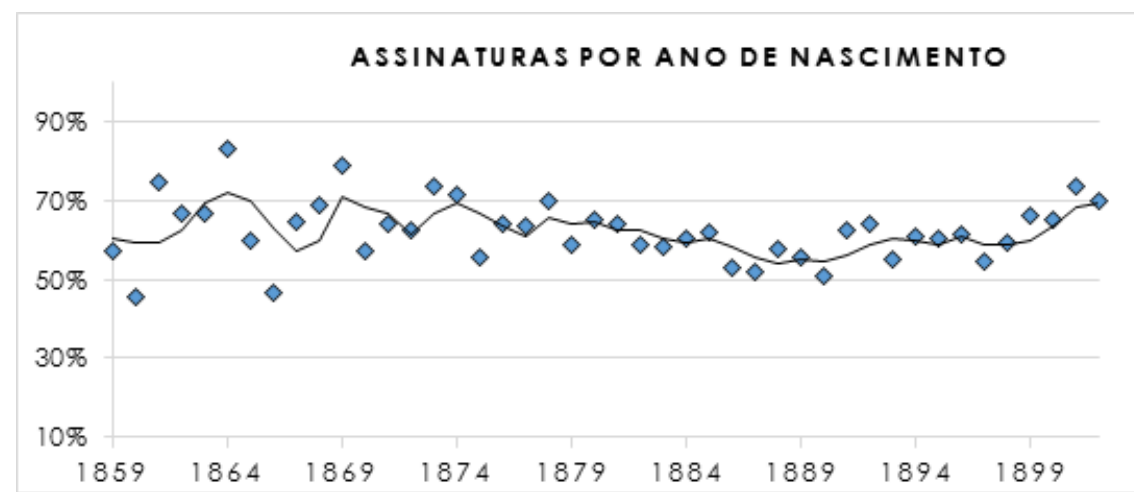

Fonte: Elaborado pelas autoras a partir dos dados obtidos nos registros civis

Infere-se que a porcentagem dos indivíduos alfabetizados varia de $51 \%$ a $70 \%$ no período estudado, mas não possui discrepâncias constantes ao longo dos anos, o que é confirmado pela linha de tendência. A temporalidade que correspondente a 43 anos é uma amostra considerável para a investigação da alfabetização de mais de uma geração e que se encontra no cerne do período migratório.

É possível compreender que o período, o contexto, as gerações e os indivíduos que compõem esta análise, em sua maioria imigrantes e seus filhos, de uma forma generalizada conseguiram manter a taxa de alfabetização e que o processo migratório não impactou nos índices de alfabetização, o que é admirável se pensarmos em suas condições iniciais. Condições do processo de viagem, da exploração e do estabelecimento no local, o que poderia ter 
impactado negativamente sua taxa de alfabetização. $\bigcirc$ resultado se contrapõe, de certo modo, às pesquisas sobre os italianos, realizadas por Gardelin e Costa (1993) que sustentam a inexistência de um ambiente para as primeiras gerações de filhos equiparado culturalmente às condições da pátria de origem, explicando o aumento do analfabetismo.

A análise desses dados levanta outras questões e hipóteses, que não são passíveis de respostas apenas por este estudo, mas que podem ser 0 embrião de novas pesquisas sobre a escolarização- indagações sobre a forma de manutenção desses índices. Afinal, houve a execução de políticas públicas para a manutenção da alfabetismo? E se não, pelo diagnóstico da presença ou ausência de aulas e escolas na localidade que amparassem a totalidade dos indivíduos em idade escolar, já que o índice não aumentou, foram essas mesmas políticas que contemplaram a manutenção da alfabetização? Ou a alfabetização ocorreu por meio informal ou mesmo familiar? Se a resposta hipoteticamente estivesse nessa última possibilidade, sinalizaria a fragilidade no que tange à execução de políticas públicas, o que não iria diferir da situação a nível nacional, em que o discurso e as legislações eram criados, mas muitas vezes não se concretizavam (INÁCIO FILHO; SILVA, 2011 ).

\section{Considerações finais}

O presente trabalho teve como objetivo analisar a taxa de alfabetização de Antônio Prado, Rio Grande do Sul, entre 1895 e 1920. Do resultado de todos os registros, obtivemos $60,85 \%$ de indivíduos que assinaram o registro civil de matrimônio, sendo alfabetizados em sua maioria, o que significa que tiveram acesso ao primeiro nível do processo de escolarização ou à alguma forma de educação. Não houve a intenção de medir a profundidade do nível de instrução, mas apresentá-lo como um indicador da alfabetização da população no período e local analisado.

Constatou-se que a análise de especificidades da taxa de alfabetização foi relevante, pois os índices variam de acordo com a nacionalidade e sexo. Existem diferenças entre as nacionalidades, algumas atingem quase $90 \%$ de analfabetismo enquanto outras são alfabetizadas em sua maioria. Mas há uma disparidade relativa ao gênero, enquanto $72,03 \%$ dos homens assinavam os documentos, as mulheres se aproximaram da marca dos $50 \%$. 
Entende-se que não é possível generalizar a resposta para a taxa de alfabetização, mas que, nesse caso, ao contrário do que parte dos trabalhos já desenvolvidos expõe, desmistifica-se a visão dos sujeitos imigrantes e seus filhos como analfabetos em sua maioria no período final do século XIX e início do XX Entendemos que esse estudo, apesar de se referir a um pequeno município, contribui tanto para pesquisa de localidades semelhantes quanto para a utilização em índices regionais ou nacionais.

Sumariamente, a conclusão é que existe a manutenção da taxa de alfabetização ao longo do período, apesar dos indivíduos serem alfabetizados em sua maioria. $\bigcirc$ processo migratório, os primeiros anos de estabelecimento e o desenvolvimento inicial da localidade não influenciaram na alfabetização das crianças imigrantes e seus filhos nascidos no Brasil. Existia alguma forma de processo educativo para tal, ademais hipoteticamente a taxa de alfabetização é equivalente à geração anterior de imigrantes.

Essas constatações abrem possibilidades de problematizações e estudos futuros para a compreensão de como ocorreu a manutenção da taxa de alfabetização. Seria necessária uma investigação do contexto para a análise pormenorizada como a questão da alfabetização na pátria de origem dos que imigraram, ou seja, uma perspectiva transnacional desta história da educação.

\section{Nota}

1 Utilizamos o termo "colono" com a designação do imigrante europeu que recebeu um lote de terra.

2 Os livros pesquisados são: Livro 1 (18.02.1895 a 20.05.1902), 2 (21.05.1902 a 09.1 1. 1908), B-3 (1 1.1 1.1908 a 03.03.1915), B-4 (20.03.1915-29.07.1918), e parte do livro 5 até a página 129 (08.08.1918-28.12.1920).

3 INEP. Mapa do analfabetismo. Ferraro e Kriedlow (2004) e índices elaborado a partir dos registros civis de Antônio Prado - somente os anos de 1900 e 1920.

4 Os índices utilizados são do INEP - Censo de 1920 (calculado na população de 15 anos ou mais). Ferraro e Kriedlow (2004) com os índices do censo de 1890 e 1920 no Rio Grande do Sul (sem informação das idades mínimas) e o índice de 1890 do Brasil (calculado na população de 5 anos ou mais). 


\section{Referências}

AHMAP. 15 ago. 1913. Documento avulso. (Recenseamento).

AHMJSA. Correspondência. 3. jul. 1890. (Arquivo Histórico Municipal João Spadari Adami (Caxias do Sul - Arquivo da Diretoria da Colônia Caxias e da Comissão de terra e Medição de lotes). Disponível em: hitp://arquivomunicipal.caxias.rs.gov.br/index.php/oficio-59. Acesso em 5 nov. 2019.

ANNUARIO da Província do Rio Grande do Sul. Annuario para o anno de 1889. Porto Alegre: Gundlach \& Cia, 1888.

ANTÔNIO Prado. Cartório de Registro Civil de Antônio Prado. Certidão de casamento de Fidelcino Magnabosco e Julia Rech. Antônio Prado, 18 nov. 1916 (Livro de Matrimônio, B-4, Fls. 177, n 93, microfilme de registros de 1895-2003 Family Search). Disponível em: https:// www. familysearch.org/ark:/61903/3:1:3QSQ-G9LC-9ZGW? $i=99 \&$ cat=263342. Acesso em: 11 nov. 2019.

ANTÔNIO PRADO. Registros civis de Antônio Prado. Family Search. (Microfilme de registros de 1895-2003). Disponível em: https://www.familysearch.org/search/catalog/263342? availability=Family\%2OHistory\%2OLibrary. Acesso em: 1 nov. 2019.

22 BARBOSA, Fidélis Dalcin. Antônio Prado e sua história. Porto Alegre: EST, 1980.

BRASIL. Decreto n ${ }^{\circ} 9.886$, de 07 de março de 1888. Coleção de Leis do Império do Brasil - 1888. (v. 1, parte 2). Disponível em: https://www2.camara.leg.br/legin/fed/ decret/1 824-1 899/decreto-9886-7-marco-1 888-542304-publicacaooriginal-50566-pe. html. Acesso em: 12 nov. 2019.

BRASIL. Decreto $n^{\circ}$ 10.044, de 22 de setembro de 1888. Coleção de Leis do Império do Brasil - 1888. (v. 2, parte 2). Disponível em: https://www2.camara.leg.br/legin/ fed/decret/1 824-1899/decreto-1 0044-22-setembro-1 888-542833-publicacaooriginal-52347-pe.html. Acesso em: 12 nov. 2019.

BRASIL. Decreto n 4.827, de 7 de fevereiro de 1924. Diário Oficial da União. Poder Legislativo, Brasília, DF, 10 fev. 1924. Seção 1, p. 4216. Disponível em: https://www2. camara.leg.br/legin/fed/decret/1920-1929/decreto-4827-7-fevereiro-1924-565566norma-pl.html. Acesso em: 12 nov. 2019.

BRASIL. Lei n 1.829, de 09 de setembro de 1870. Coleção de Leis do Império do Brasil - 1870. (v. 1). Disponível em: hitp://legis.senado.leg.br/norma/543582/publicacao/15631205. Acesso em: 3 nov. 2019. 
BRASIL. Diretoria Geral de Estatística. Estatística da instrucção. Primeira parte: estatística escolar, 1916. Rio de Janeiro: Typographia da Estatistica, 1916. (v. 1). Disponível em: https://biblioteca.ibge.gov.br/visualizacao/monografias/GEBIS\%20-\%2ORJ/estatisticainstruccao_v1.pdf. Acesso em: 15 nov. 2019.

BURKE, Peter. A escrita da história: novas perspectivas. São Paulo: EdUNESP. 1992.

CATANI, Denice Barbara; FARIA FILHO, Luciano Mendes de. Um lugar de produção e a produção de um lugar: a história e a historiografia divulgadas no GT História da Educação da ANPEd (1985-2000). Revista Brasileira de Educação, Rio de Janeiro, n. 19, p. 113 128. 2002. Disponível em: http://www.scielo.br/pdf/rbedu/n19/n19a09.pdf. Acesso em: 15 nov. 2019.

CERTEAU, Michel de. A escrita da história. 2. ed. Rio de Janeiro: Forense Universitária, 2002.

CHARTIER, Roger. As práticas da escrita. In: CHARTIER, Roger. História da vida privada 3: da Renascença ao Século das Luzes. São Paulo: Companhia das Letras, 1991.

DE BONI, Luis Alberto; COSTA, Rovílio. Os italianos no Rio Grande do Sul. 3. ed. Porto Alegre: Edições EST/Caxias do Sul: Correio Riograndense/ EDUCS, 1984.

ESTATISTICA Demographica. Quadro estatístico da população e densidade demográfica do Estado (por município). Staffeta Rio Grandense. Villa Garibaldi/ Conde d'Eu, v. 10, n. 30, p. $1-31$ out. 1918.

FEBVRE, Lucien. Combates pela história. Lisboa: Presença, 1989.

FERRARO, Alceu Ravanello; KREIDLOW, Daniel. Analfabetismo no Brasil: configuração e gênese das desigualdades regionais. Educação e Realidade, Porto Alegre, v. 29, n. 2, p. 179-200, jul./dez. 2004. Disponível em: https://seer.ufrgs.br/educacaoerealidade/ article/view/25401. Acesso em: $1^{\circ}$ nov. 2019.

FERRARO, Alceu Ravanello. Analfabetismo e níveis de letramento no Brasil: o que dizem os censos? Educação \& Sociedade. Campinas, v. 23, n. 81 , p. 21-47. 2002. Disponível em: http://www.scielo.br/scielo.php?script=sci_arttext\&pid=S0 $101-73302002008100003$. Acesso em: 2 nov. 2019.

INÁCIO FILHO, Geraldo; SILVA, Maria Aparecida da. Reformas educacionais durante a Primeira República no Brasil (1889-1930). In: SAVIANI, Demerval (org.). Estado e políticas educacionais na história da educação brasileira. Vitória: EDUFES, 2011. 
A taxa de alfabetização de Antônio Prado, Rio Grande do Sul (1 895-1920)

GARDELIN, Mário; COSTA, Rovílio. Colônia Caxias: origens. Caxias do Sul: Edições EST, 1993.

GASTAL, Susana; BEBER, Ana Maria Costa; SÁ, Felipe Zaltron de. Gastronomia da italianidade: diversidade, tradição e inovação em Antônio Prado, Brasil. Revista de Turismo Contemporâneo, Natal, v. 5, n. 21 , ago. 2017. Disponível em: https://periodicos.ufrn.br/ turismocontemporaneo/article/view/12541. Acesso em: 15 nov. 2019.

GIRON, Loraine Slomp. Caxias do Sul: evolução histórica. Caxias do Sul: EST/UCS, 1977.

INEP. Instituto Nacional de Estudos e Pesquisas Educacionais Anísio Teixeira. Mapa do Analfabetismo no Brasil. 2000. Disponível em: http://inep.gov.br/

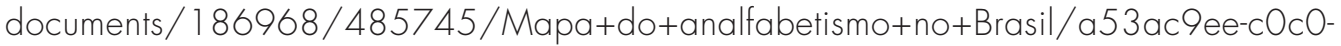
4727-b2 16-035c65c45el b?version=1.3. Acesso em: 25 out. 2019.

KREUTZ, Lúcio. A educação de imigrantes no Brasil. In: LOPES, Eliane Marta Santos Teixeira; FARIA FILHO, Luciano Mendes de; VEIGA, Cynthia Greive (org.). 500 anos de educação no Brasil. 2. ed. Belo Horizonte: Autêntica, 2000.

LUCHESE, Terciane Ângela. O processo escolar entre imigrantes da Região Colonial Italiana do RS - 1875 a 1930: leggere, scrivere e calcolare per esserealcunonellavita. 24 2008. 495 f. Tese (Doutorado em Educação) - Programa de Pós-Graduação em Educação, Universidade do Vale do Rio dos Sinos, São Leopoldo, 2008. Disponível em: http://www. repositorio.jesuita.org.br/handle/UNISINOS/2068. Acesso em: 8 jan. 2019.

PAIVA, Vanilda Pereira. História da educação popular no Brasil: educação popular e educação de adultos. 6. ed. rev. e ampl. São Paulo: Loyola, 2003.

PAZUCH, Giovane. Imigração italiana na colônia de Antônio Prado - RS: catolicismo e sociabilidades (1 885-1945). 2015. 173 f. Dissertação (Programa de Estudos Pós-Graduados em História) - Pontifícia Universidade Católica de São Paulo, São Paulo, 2015. Disponível em: https://tede2.pucsp.br/handle/handle/12901. Acesso em: 20 mar. 2019.

PETROCCHI, Luigi. Le colonie italiane del distretto di Bento Gonçalves (Rio Grande do Sul). BE - Bollettino dell'emigrazione. 1904. p. 15-16. In: HERÉDIA, Vania Beatriz Merlotti; ROMANATO, Gianpaolo. Fontes Diplomáticas: Documentos da imigração italiana no Rio Grande do Sul. 2017 (Tomo II). Disponível em: https://www.ucs.br/site/editora/e-books/ historia-e-imigracao/. Acesso em: 4 abr. 2019.

PIAZZA, Cleodes Maria; RIBEIRO, Júlio. Anotações de literatura e de cultura regional. Caxias do Sul: EDUCS, 2005. 
POSSAMAI, Paulo César. "Dall'Itáliasiamopartiti": a questão da identidade entre os imigrantes italianos e seus descendentes no Rio Grande do Sul (1875-1945). Passo Fundo: EPF Editora, 2005.

RAGAZZINI, Dario. Para quem e o que testemunham as fontes da História da Educação? Educar em Revista, Curitiba, v. 17, n. 18, p. 13-28, dez. 2001 . Disponível em: https:// revistas.ufpr.br/educar/article/view/32815/20799. Acesso em: 20 maio 2019.

SILVA, Thiago Fernando Sant'Anna e. Gênero, história e educação: a experiência de escolarização de meninas e meninos na província de Goiás (1 827-1889). 2010. 240 f. Tese (Doutorado em História) - Programa de Pós-Graduação em História, Universidade de Brasília, Brasília, 2010. Disponível em: https://repositorio.unb.br/handle/10482/8651. Acesso em: 10 nov. 2019.

TIMM, Jordana Wruck. A relação escola/comunidade na região das antigas colônias italianas, nordeste do Rio Grande do Sul, 1915 a 1960. 2013. Dissertação (Mestrado) - Programa de Pós-Graduação em Educação. Universidade de Caxias do Sul, 2013. Disponível em: https://repositorio.ucs.br/xmlui/handle/11338/461 ? show=full. Acesso em: 11 nov. 2019.

VEIGA, Cynthia Greive. História da educação. São Paulo: Ática, 2007.

VINCENT, David. Alfabetização e desenvolvimento. Revista Brasileira de Educação, Rio de Janeiro, v. 19, n. 58, p. 539-560, 2014. Disponível em: http://www.scielo.br/scielo. php?pid=S 141 3-24782014000800002\&script=sci_abstract\&tlng=pt. Acesso em: 23 out. 2019. 
Mestranda Manuela Ciconetto Bernardi Universidade de Caxias do Sul (Caxias do Sul - Brasil)

Programa de Pós-Graduação em Educação Grupo de Pesquisa História da Educação, Imigração e Memória (GRUPHEIM) Orcid id: https: / / orcid.org/0000-0002-01 30-4845 E-mail: mcbernardi1@ucs.br

Profa. Dra Terciane Ângela Luchese Universidade de Caxias do Sul (Caxias do Sul - Brasil) Programa de Pós-Graduação em Educação Grupo de Pesquisa História da Educação, Imigração e Memória (GRUPHEIM) Orcid id: https: / / orcid.org/0000-0002-6608-9728 E-mail: taluches@ucs.br Recebido 5 mar. 2020 Aceito 27 maio 2020 